Article

\title{
Linear Model Predictive Control for Physical Attractiveness and Risk: Application of Cosmetic Medicine Service
}

\author{
Li-Ling Liu \\ Department of Business Administration, CTBC Business School, No. 600, Sec. 3, Taijiang Blvd., Annan District, \\ Tainan 709, Taiwan; karenliu@nccu.edu.tw
}

Received: 12 May 2020; Accepted: 10 June 2020; Published: 15 June 2020

check for updates

\begin{abstract}
In the online world, the "eyeball economy" has become mainstream. Whether regarding Internet cosmetic medicine endorsers or physical service providers, the topic of physical attractiveness has long been discussed in the field of medical beauty e-commerce. When receiving cosmetic medical services, consumers have frequent contact with employees. Physical attractiveness is the most apparent and easily observed employee characteristic, and consumers base their judgement and behavior on it. In this study, the relationship between the physical attractiveness of cosmetic service employees and consumers' perceived risk is discussed and clarified. After 366 questionnaires were collected and analyzed, the results indicated that the physical attractiveness of cosmetic service employees was negatively associated with perceived financial, performance, physical, psychological, and social risk. The study offers suggestions for employers. They should recruit more attractive employees. This will increase consumer intention to purchase a service because the consumers' perceived risks are reduced. It may also enhance repurchase intention and consumption frequency.
\end{abstract}

Keywords: medical beauty e-commerce; cosmetic medicine; physical attractiveness; risk

\section{Introduction}

The new generation will account for $29.5 \%$ of China's population in 2020, while accounting for $53 \%$ of consumption in the country [1]. The growth in consumption among the new generation parallels the rapid development of the Internet, giving the generation characteristics such as chasing personality trends, attending to quality of life, and paying attention to appearance [1]. For example, with the continuous development of social networks, harvesting "praise" through self-picture, edit-image, and picture-spreading has become an essential feature of the new generation. The emphasis on the "beauty economy" is becoming another outlet in the Internet industry [1].

TaoBao released an economic report stating that spending by beauty consumers exceeded US $\$ 15$ million in 2018, and the trend was clearest among young people. In January 2020, the Mobile Institute reported that the number of active users of the Beauty Economics app in mainland China was nearly 60 million in 2019 [2].

Beauty is measured on the basis of physical attractiveness, perceptions of which have been confirmed in numerous experiments [3-5]. Attractive people generally experience an easier life; the door to success is opened by perfect bone structure and a sparkling smile [6].

The China Business Industry Research Institute announced that the Chinese cosmetic medicine market amounted to US \$24.8 billion in 2018 and was estimated to exceed US \$36.1 billion in 2020 . Medical beauty e-commerce is currently in the stage of user accumulation and market education. Its market size is estimated to reach US $\$ 2.8$ billion and to account for $8 \%$ of the cosmetic medicine industry market in 2020. This indicates that medical beauty e-commerce will represent a sizeable 
market in the future [2]. Through medical cosmetics e-commerce, consumers can obtain information in advance to facilitate decision-making before basic face-to-face consultation [7].

Cosmetic medicine combines medical professionalism and beauty techniques with a focus on noninvasive medical technology for improving or changing physical appearance or shape for cosmetic purposes [8]. The cosmetic medicine industry is a service industry; therefore, the medical knowledge, beautification skills, and physical attractiveness of cosmetic medical service providers play central roles in the industry. A service employee's physical attractiveness is especially conspicuous and is the most easily observed personal characteristic [9]. Consumers may have a preliminary attitude or due to an employee's physical appearance or have expectations regarding an employee's appearance based on previous experience or impressions [10].

Past studies have discussed physical attractiveness and consumer outcomes. Greater physical attractiveness brings with it advantages [11] because physically attractive individuals have more friendships [12] and experience greater tolerance [4], favorable bias [5], and positive reactions [13]. The use of attractive models in advertising can result in higher consumer reliability [14] and more favorable advertising comments [15]. Positive illusions regarding a partner's attractiveness mediate the link between creativity and the risk of passion decline [16]. However, physical attractiveness stereotyping and the attractiveness halo effect were invalid for internal auditors' experiences and motivation [17].

Cosmetic medical services are an industry related to attractiveness. The physical attractiveness of service personnel affects consumers' evaluations $[18,19]$. However, whether physical attractiveness is related to risk has never been discussed. The aim of the present study is to realize the gap in the literature regarding how the physical attractiveness of cosmetic medicine servicers relates to consumers' perceived risk.

\section{Literature Review}

Cosmetic medicine is an emerging medical industry. The use of technology in the industry covers clinical departments related to beauty care [8]. Advances in medical technology and biotechnology have enabled the development of effective solutions to skin defects and illnesses. Cosmetic medicine is convenient, safe, and relatively accessible in terms of cost. Thus, the industry is thriving [8].

Reasons for the popularity of cosmetic surgery include technical advances in cosmetic medicine, lower cost of medical treatment, a socioeconomic environment in which people have more disposable income, and greater attention being paid to appearance. Consumers choose to change their appearance because of negative thoughts, feelings, or experiences, and cosmetic medicine allows them to improve their relationships and change social perceptions of them. Therefore, the psychological state of these consumers before the use of cosmetic medicine should be explored [20]. People believe that they can feel better about themselves, enhance their interpersonal skills, improve their self-esteem and emotional stability, and even become more confident if they undergo cosmetic medical treatment [21]. In cosmetic medicine, however, a difference can exist between what the patient was expecting and the actual result, with some patients claiming they have been damaged. This damage is a risk that consumers should realize in advance [22].

\subsection{Physical Attractiveness}

Physical attractiveness refers to "the pleasing degree of the target person" [9]. In interpersonal relationships, most people notice appearance, and this appearance often affects their perception or triggers favorable feelings [23]. Whether through static or dynamic attraction [24], physical attractiveness causes a positive emotional response in others, produces positive reinforcement effects, and triggers behavior intended to foster closeness [25]. Physical attractiveness conveys the ideal image of the individual mind, which can lead to profound feelings of pleasure [26].

From socialization, social expectancy, implicit personality, and evolutionary perspectives, more physically attractive individuals always inherently possess and come to develop more positive 
personality traits $[27,28]$. People attribute more positive qualities (social skills, potency, adjustment, intelligence, and trustworthiness) [29,30] to physically attractive individuals because of physical attractiveness stereotyping and the halo effect [31].

From a social psychology perspective, most people tend to choose those with an attractive appearance when seeking to develop long-term relationships. First, from the aesthetic perspective, people love beautiful people; second, people have more expectations of reward when in contact with more attractive people; and third, due to the stereotyping of attraction-namely, the concept of "what is beautiful is good"- people tend to believe that attractive people have other good traits [32].

Physical attractiveness is the most obvious and observable characteristic of service personnel $[9,33]$. The attitudes and reactions of consumers may differ according to the physical attractiveness of service personnel. Numerous studies have also suggested that physical attractiveness has a significant influence on consumer judgement and behavior [34]. A service employee's appearance can affect consumer behavior [15] and convey service messages [34].

\subsection{Perceived Risk}

Consumer purchases may lead to unpredictable results that can be considered risks [35]. Therefore, consumption behavior is the taking of a risk. Consumer perceptions of uncertainty or unfavorable results [36] and individual evaluations of situational uncertainty and degree of controllability [37] are perceived risks. Therefore, perceived risk refers to both the probability of a consumer's perception of unfavorable results after a purchase and the subjective perception of the degree of loss when the purchase fails to meet the expected goals [38].

Studies on service products have demonstrated that perceived risk is a factor in situational and personal consumption behavior and affects the purchase of commodities and services as well as the selection of stores. When a consumer has a certain need and collects and compares brand information, they learn about differences among brands and may perceive risks $[39,40]$. The consumer's perceived risk and the degree of risk they will tolerate determine their purchase strategy, purchase intention [41], and purchase behavior [42].

\subsection{Research Hypotheses}

Match-up theory suggests a congruence, or "fit", between a product and its endorsers [43]. Associative learning theory suggests that distinct information and concepts can become linked when they are repeatedly paired together; the recollection of one concept prompts automatic recall of the other, associated concept [43].

According to these theories, when the type of service is associated with attractiveness, a consumer is more willing to pay for the service if the service employee is more physically attractive [10]. Cosmetic medicine is a service related to attractiveness, and a more attractive service employee better promotes the image of professional service and enhances consumer recognition and perceived trust [44]. Trustworthiness affects, monitors, and guides actions and attitudes in consumer interactions and is a subjective state [45]. Furthermore, perceived trustworthiness reduces suspicion and increases openness toward an individual [46]. Jacoby and Kaplan (1972) suggested that consumers perceive financial risk as the risk associated with all costs and expenses associated with attaining a product and their uncertainty about the product [47]. This risk is measured with money [48]. Thus, it is hypothesized that, for the purchase of services that are risky due to their very nature, consumers rely on cues drawn from the salesperson with whom they are interacting to obtain additional information about the service and reduce risks associated with the purchase. The similarity of the service provider to the consumer should increase the amount of trust and satisfaction the consumer places in the service provider, resulting in more positive outcomes of the exchange [49]. On this basis, we put forward the following hypothesis. 
Hypothesis 1. A consumer's perceived financial risk is lower when a service employee is more physically attractive.

Perceived performance risk is the risk associated with the uncertainty that the product will not perform as expected. Perceived physical risk is the possibility that a product will be dangerous to the user [47]. Base on bounded rationality theory, when cosmetic medicine decision-makers lack the ability and resources to obtain optimal solutions, they apply rationality only after considerable simplification of the available choices [50]. If the service employee is more physically attractive, they can better display a positive image and high degree professionalism. Consumers evaluate the professional expertise of service personnel and are more interested in information and cues provided by highly professional sales personnel [51]. Therefore, when the consumer can stratify the service provider's level of professionalism, the interference effect of consistency, as generated by the risk of purchase decision-making behaviors [38], is decreased [52]. Therefore, hypotheses 2 and 3 are put forward as follows.

Hypothesis 2. A consumer's perceived performance risk is lower when a service employee is more physically attractive.

Hypothesis 3. A consumer's perceived physical risk is lower when a service employee is more physically attractive.

Cognitive theory focuses on the psychometrics of risk. Whereas the psychometric approach searches the choices required, the cognitive psychological approach questions on how people reason in conditions where they possess little knowledge of risks [53]. During the process of purchasing a product or receiving a service, the most prominent cue is the appearance of the service employee [54]. An attractive physical appearance can induce a positive emotional response, generate positive enhancement effects, and trigger similar behaviors in others [25]. Perceived psychological risk is the possibility that a product will not comply with the consumer's self-image [47]. People are often affected by the halo effect of "what is beautiful is good", assuming that attractive people have other good traits [32]. Consistently, hypothesis 4 is formulated and proposed as follows.

Hypothesis 4. A consumer's perceived psychological risk is lower when a service employee is more physically attractive.

Cosmetic medicine is an industry related to beauty. When the service employee's physical attractiveness increases, the consumer's preference also increases [10]. In addition, more physically attractive service employees are regarded as having better sales skills [18], resulting in higher consumer evaluations [19], which can enhance consumer interaction and purchase intention [18]. Therefore, subject to the halo effect, as the level of a service employee's physical attractiveness increases, consumers have increasingly positive impressions to convince around relatives and friends regarding the cosmetic medicine image and service, which can also affect perceived social risk [42]. According to the cultural theory of risk, the type of perceived risk varies according to location, occupation, and lifestyle, between individuals of the same age and gender, and also between nationalities [55] (Rohrmann 1994). Perceived social risk refers to the possibility that the use of a product will affect the way others think of the user [47]. Consistently, hypothesis 5 is put forward as follows.

Hypothesis 5. A consumer's perceived social risk is lower when a service employee is more physically attractive. 


\section{The Methodology}

\subsection{Setting and Sample}

This study is a sort of quota sampling. The sample comprised outpatients of cosmetic and laser centers in regional teaching hospitals, regional hospitals, and medical centers. Each research location included five hospitals in northern, central, and southern Taiwan; 60 questionnaires were distributed to each hospital. Calling and asking the hospital personnel department assisted to survey the questionnaire in the clinic. All 900 participants who had the experience of cosmetic medicine treatment were provided assurance of confidentiality and were told that the questionnaire items did not have right or wrong answers. The respondents self-administered the questionnaires. By the cut-off date for data collection, 366 questionnaires had been retrieved for a response rate of $40.6 \%$.

To minimize the effect of common method variance (CMV), three approaches were employed in designing the questionnaire. First, open-ended questions were interspersed throughout the questionnaire so that the respondents did not fall into a pattern linked to Likert or semantic differential scales. Second, the anchors of the scales varied by construct. Third, some items were reverse coded. After collecting the data, Harman's one-factor test was used to test for CMV. If CMV was a severe problem, a single factor would be expected to emerge from factor analysis or one general factor would account for most of the covariance in the criterion variables [56]. Factor analysis was performed on all items, extracting six factors with eigenvalues greater than 1 . Furthermore, no general factor was apparent in the unrotated factor structure, with Factor 1 accounting for less than $20 \%$ of the variance. Thus, the design of the questionnaire and the post hoc test suggested that CMV was not a severe concern.

\subsection{Measures}

The independent variable was physical attractiveness, and the dependent variables were types of perceived risk (financial, performance, physical, psychological, and social risk).

\subsubsection{Physical Attractiveness}

The scale used to evaluate whether a particular person is attractive and measure the importance of physical attractiveness consisted of five items from Ohanian (1990) [57]. The 5-point Likert scale used to score the scale ranged from "strongly disagree" (1) to "strongly agree" (5). A higher score indicated a higher prominence of attractiveness. An example item was "I think that cosmetic medical service personnel should be attractive in appearance" $(\alpha=0.928)$.

\subsubsection{Financial Risk}

Financial risk was measured using two items of the inventory developed by Jacoby and Kaplan (1972) [47]. The 5-point Likert scale ranged from "strongly disagree" (1) to "strongly agree" (5). An example item was "The cosmetic medical service I received can be purchased at a lower price" $(\alpha=0.871)$. 


\subsubsection{Performance Risk}

Performance risk was measured using the two-item scale developed by Jacoby and Kaplan [47]. A 5-point Likert scale was employed for scoring. The item was "The cosmetic medical service I received is not as good as the service employee claimed" $(\alpha=0.901)$.

\subsubsection{Physical Risk}

Physical risk was measured using the inventory developed by Jacoby and Kaplan [47]. The scale consisted of two items measured on a 5-point Likert scale. One item was "The cosmetic medical service I received may have caused me damage" $(\alpha=0.778)$.

\subsubsection{Psychological Risk}

Psychological risk was measured using the scale developed by Jacoby and Kaplan [47]. The scale was composed of two items measured on a 5-point Likert scale. One item was "The cosmetic medical service I received is not in line with my personal style" $(\alpha=0.847)$.

\subsubsection{Social Risk}

Social risk was measured using the two-item scale developed by Jacoby and Kaplan [47]. The scale was measured using a 5-point Likert scale. One item was "I am afraid that my family and friends do not agree that I should have had the cosmetic medical service" $(\alpha=0.786)$.

The questionnaire was originally prepared in English and then translated into Chinese using the back-translation method [58]. The instrument was finalized on the basis of feedback from a pilot sample of 30 outpatients in the research locations. The respondents in the pilot sample had no difficulty understanding the items in the survey instrument. Therefore, no compelling reason to revise the questionnaire was identified.

\subsection{Methods}

First, descriptive analysis was used for all respondent characteristics. Second, to assess the direct and indirect relationships between physical attractiveness and the types of risk, the scales were subjected to confirmatory factor analysis (CFA) structural equation modeling (SEM) by using AMOS 25 to address issues related to dimensionality and convergent and discriminant validity [59]. The measures were also subjected to Cronbach's alpha and Pearson product-moment correlation analyses by using SPSS 17.0 to provide support regarding issues of internal consistency and discriminant validity. Third, analysis of variance was used to calculate risk according to gender, age, education, and salary. Fourth, correlation analysis was used to clarify the relationships within all demographics, constructs, and variables. Last, the nested model approach was employed. This approach was used by others using SEM to examine models [60]. In this approach, the paths from physical attractiveness to risks were estimated. The hypothesized relationships were measured using AMOS 25 for path analysis.

\section{Results}

\subsection{Characteristics of the Respondents}

Table 1 details the characteristics of the respondents. In all, $68.3 \%$ of the respondents were women, $50.5 \%$ were between the ages of 41 and 60 years, $53.8 \%$ had a university degree, and $41 \%$ reported an annual income of US $\$ 33,333$ or less. 
Table 1. Characteristics of the respondents $(\mathrm{N}=366)$.

\begin{tabular}{lll}
\hline & \multicolumn{1}{c}{ Frequency } & Percentage \\
\hline Gender & 116 & \\
Male & 250 & 31.7 \\
Female & & 68.3 \\
\hline Age (Years) & 9 & \\
Under 20 & 121 & 2.5 \\
$\quad$ 21-40 & 185 & 33.1 \\
$\quad 41-60$ & 51 & 50.5 \\
Above 60 & & 13.9 \\
\hline Education & 63 & \\
High school & 197 & 17.2 \\
University & 106 & 53.8 \\
Graduate & & 29.0 \\
\hline Occupation & 100 & \\
Civil servant & 26 & 27.3 \\
Health care & 76 & 7.1 \\
Business & 50 & 20.8 \\
Homemaker & 41 & 13.7 \\
Student & 40 & 11.2 \\
Retiree & 33 & 10.9 \\
Other & & 9.0 \\
\hline Monthly salary & 89 & 24.3 \\
Under NT\$50,000 & 150 & 41.0 \\
50,001-100,000 & 30 & 1.6 \\
100,001-150,000 & 6 & 24.9 \\
150,001-200,000 & 91 & \\
Above 200,000 & & \\
\hline & & \\
\hline
\end{tabular}

\subsection{Psychometric Properties of the Measures}

The measures were subjected to a series of CFAs to address issues of dimensionality and convergent and discriminant validity. In light of the results, several items were removed owing to low standardized loadings (of $<0.50$ ) or nonsignificant $t$-values. Deletion of items is widely used for scale purification, and similar patterns may be observed in other empirical studies [61]. As Table 2 demonstrates, the standardized loadings (ranging from 0.643 to 0.961 ) and all t-values (from 2.607 to 17.586) were significant (e.g., comparative fit index $\mathrm{CFI}=0.899$, root-mean-square residual $\mathrm{RMR}=0.043$ ). All 15 items had standardized loadings greater than 0.70 . The magnitudes of the loadings, with their significant $t$-values, provide evidence of convergent validity. The composite reliability scores ranged between 0.9 and 0.93 (all >0.6). The values of average variance extracted all exceeded 0.5 [59].

In addition, a series of pairwise CFAs was employed to assess discriminant validity. We first fit a two-dimensional model to each pair of the study constructs and then forced the items representing each factor into a single factor solution. Various fit statistics produce better results for a two-factor model. The results strongly suggested that each set of items represented a single underlying construct, providing evidence of discriminant validity [59]. Internal consistency analysis was performed by computing the coefficient $\alpha$ for each construct. As detailed in Table 2, almost all values of $\alpha$ were greater than the benchmark of 0.70 recommended by Nunnally (1978) [62]. 
Table 2. Scale items, reliabilities, and confirmatory factor analysis results.

\begin{tabular}{|c|c|c|c|}
\hline Scale Items & Standardized Loadings & $\mathbf{t}$ & Alpha \\
\hline Physical Attractiveness & & & 0.9289 \\
\hline $\begin{array}{l}\text { I think cosmetic medical service personnel should be } \\
\text { attractive in appearance }\end{array}$ & 0.875 & 11.575 & \\
\hline $\begin{array}{l}\text { I think that cosmetic medical service personnel } \\
\text { should be fashionable in appearance }\end{array}$ & 0.922 & 9.248 & \\
\hline $\begin{array}{l}\text { I think that cosmetic medical service personnel } \\
\text { should be handsome/beautiful }\end{array}$ & 0.937 & 8.010 & \\
\hline $\begin{array}{l}\text { I think that cosmetic medical service personnel } \\
\text { should be elegant }\end{array}$ & 0.922 & 9.438 & \\
\hline $\begin{array}{l}\text { I think that cosmetic medical service personnel } \\
\text { should be sexy in appearance }\end{array}$ & 0.757 & 13.359 & \\
\hline Financial Risk & & & 0.8717 \\
\hline $\begin{array}{l}\text { The price of the cosmetic service I received is too } \\
\text { high and is not worth the cost }\end{array}$ & 0.877 & 13.081 & \\
\hline $\begin{array}{l}\text { The cosmetic medical service I received can be } \\
\text { purchased at a lower price }\end{array}$ & 0.864 & 11.295 & \\
\hline Performance Risk & & & 0.9011 \\
\hline $\begin{array}{l}\text { The cosmetic medical service I received is not as } \\
\text { good as the service employee claimed }\end{array}$ & 0.833 & 10.019 & \\
\hline $\begin{array}{l}\text { The cosmetic service I received is not in line with my } \\
\text { personal needs }\end{array}$ & 0.961 & 12.607 & \\
\hline Physical Risk & & & 0.7786 \\
\hline $\begin{array}{l}\text { The cosmetic medical service I received may have } \\
\text { caused me damage }\end{array}$ & 0.802 & 12.449 & \\
\hline $\begin{array}{l}\text { I am concerned about the safety of the cosmetic } \\
\text { medical service }\end{array}$ & 0.754 & 11.601 & \\
\hline Psychological Risk & & & 0.8472 \\
\hline $\begin{array}{l}\text { The cosmetic medical service I received is not in line } \\
\text { with my personal style }\end{array}$ & 0.787 & 11.222 & \\
\hline $\begin{array}{l}\text { The cosmetic service I received is not in line with my } \\
\text { status }\end{array}$ & 0.878 & 7.570 & \\
\hline Social Risk & & & 0.7865 \\
\hline $\begin{array}{l}\text { I am afraid that my family and friends do not agree } \\
\text { that I should have had the cosmetic medical service }\end{array}$ & 0.882 & 9.359 & \\
\hline $\begin{array}{l}\text { I am afraid that my friends and family will laugh at } \\
\text { me for receiving the cosmetic medical service }\end{array}$ & 0.643 & 17.586 & \\
\hline
\end{tabular}

The results of the analysis of variance showed that perceived financial risk, performance risk, physical risk, psychological risk, and social risk differed significantly between genders $(p=0.012$, $p<0.05)$. The perceived financial risk, performance risk, and physical risk were higher for female cosmetic medicine consumers than for male consumers (mean $=8.31$ vs. $7.25,8.42$ vs. 7.00 , and 8.13 vs. 6.92 , respectively). Perceived psychological risk and social risk were higher for male cosmetic medicine consumers than for female consumers (mean $=8.00$ vs. 6.82 and 8.22 vs. 7.22 , respectively). Perceived financial risk differed significantly between ages $(p=0.041, p<0.05)$. Perceived financial risk was greater for cosmetic medicine consumers aged older than 60 years than for those aged younger than 20 years (mean $=7.67 \mathrm{vs}$. 6.50 ). Social risk differed significantly according to education $(p=0.011, p<0.05)$. The perceived social risk for cosmetic medicine consumers who had graduated was higher than for consumers attending high school (mean $=7.47$ vs. 6.40). Perceived performance risk differed significantly according to income $(p=0.040, p<0.05)$. Perceived performance risk was higher for consumers with incomes exceeding NT\$200,000 than for consumers with incomes of less than NT\$50,000 (mean $=7.32$ vs. 6.40). 


\subsection{Correlation Analysis}

Composite scores for each construct were computed by averaging the scores across items representing that construct. As can be observed in Table 3, the coefficients of the correlations among the study constructs ranged from 0.035 (gender and age) to 0.526 (financial and performance risk). None of the correlation coefficients were equal to or higher than 0.90 [63], providing further evidence of discriminant validity. The means and standard deviations of the composite scores are also provided in Table 3.

Table 3. Correlation of all variables $(\mathrm{N}=366)$.

\begin{tabular}{|c|c|c|c|c|c|c|c|c|c|c|c|c|}
\hline Variable & Mean & SD & 1 & 2 & 3 & 4 & 5 & 6 & 7 & 8 & 9 & 10 \\
\hline 1. Gender & 0.70 & 0.50 & 1 & & & & & & & & & \\
\hline 2. Age & 48.17 & 8.76 & 0.035 & 1 & & & & & & & & \\
\hline 3. Education & 1.78 & 0.45 & -0.080 & 0.143 ** & 1 & & & & & & & \\
\hline 4. Pay & 1.74 & 0.95 & $0.203 * *$ & $0.443 * *$ & 0.061 & 1 & & & & & & \\
\hline $\begin{array}{l}\text { 5. Physical } \\
\text { attractiveness }\end{array}$ & 1.72 & 0.26 & $0.122 *$ & $-0.326^{* *}$ & 0.043 & -0.004 & 1 & & & & & \\
\hline 6. Financial risk & 3.41 & 0.84 & $0.188 * *$ & $0.102 *$ & -0.059 & 0.081 & $-0.148^{* *}$ & 1 & & & & \\
\hline 7. Performance risk & 3.67 & 0.71 & $0.208^{* *}$ & 0.085 & -0.010 & $0.113 *$ & $-0.114^{*}$ & $0.526^{* *}$ & 1 & & & \\
\hline 8. Physical risk & 3.62 & 0.78 & $0.220 * *$ & -0.007 & 0.070 & 0.067 & $-0.116^{*}$ & $0.330 * *$ & $0.461 * *$ & 1 & & \\
\hline 9. Psychological risk & 3.63 & 0.66 & -0.124 * & -0.064 & 0.044 & -0.080 & $-0.190 * *$ & $0.114^{*}$ & $0.135 *$ & $0.138^{*}$ & 1 & \\
\hline 10. Social risk & 3.72 & 0.71 & -0.104 * & -0.006 & $0.147^{* *}$ & 0.032 & $-0.113 *$ & $0.158^{* *}$ & $0.137^{* *}$ & 0.154 * & $0.418^{* *}$ & 1 \\
\hline
\end{tabular}

Gender was significantly positively correlated with financial, performance, and physical risk ( $r=0.188,0.208$, and 0.220 , respectively; $p<0.01)$ and negatively correlated with psychological and social risk $(\mathrm{r}=-0.124$ and $-0.104 ; p<0.05)$. Age was significantly positively correlated with financial risk $(r=0.102, p<0.05)$. Educational attainment as significantly positively correlated with social risk $(\mathrm{r}=0.147, p<0.01)$. Finally, income was significantly positively correlated with performance risk $(\mathrm{r}=0.113, p<0.05)$.

\subsection{Path Analysis}

The hypothesized relationships were tested using AMOS 25 and path analysis. The model fit statistics, presented in Table 4 , collectively demonstrated that the research model favorably fit the data $X^{2}=43.4$, degrees of freedom $=10, p=0.000 ; C F I=0.917$, normed fit index NFI $=0.922$, goodness-of-fit index GFI $=0.909$, and adjusted GFI AGFI $=0.901$ ). The results of the path analysis indicated that the five hypotheses proposed in the study were supported (illustrated in Figure 1). H1 states that physical attractiveness negatively affects perceived financial risk $(\beta=-0.52, p<0.05)$. H2 states that physical attractiveness negatively affects performance risk $(\beta=-0.58, p<0.05)$. H3 states that physical attractiveness has a negative effect on physical risk $(\beta=-0.25, p<0.05)$. H4 states that physical attractiveness has a negative impact on psychological risk $(\beta=-0.32, p<0.05)$. H5 states that physical attractiveness negatively affects social risk $(\beta=-0.29, p<0.05)$. 
Table 4. Model test results. CFI, comparative fit index; NFI, normed fit index; GFI, goodness-of-fit index; AGFI, adjusted GFI; RMR, root-mean-square residual.

\begin{tabular}{lccc}
\hline \multicolumn{1}{c}{$\begin{array}{c}\text { Control Variables and Hypothesized } \\
\text { Relationships }\end{array}$} & $\begin{array}{c}\text { Standardized Parameter } \\
\text { Estimates }\end{array}$ & t-Values & Accepted/Rejected \\
\hline $\begin{array}{l}\text { Impact on risk } \\
\text { Control variable }\end{array}$ & & & \\
$\quad$ Gender & 0.038 & 1.220 & N/A \\
$\quad$ Age & $0.109^{*}$ & 2.626 & N/A \\
$\quad$ Education & 0.005 & 0.064 & N/A \\
$\quad$ Salary & -0.007 & -0.097 & H1-accepted \\
Physical attractiveness $\rightarrow$ financial risk & $-0.52^{* *}$ & -12.48 & H2-accepted \\
Physical attractiveness $\rightarrow$ performance risk & $-0.58^{* *}$ & -3.92 & H3-accepted \\
Physical attractiveness $\rightarrow$ physical risk & $-0.25^{* *}$ & -4.88 & H4-accepted \\
Physical attractiveness $\rightarrow$ psychological risk & $-0.32^{* *}$ & -5.69 & H5-accepted \\
Physical attractiveness $\rightarrow$ social risk & $-0.29 * *$ & -5.69 & \\
$\mathrm{R}^{2}=0.035$ & & & \\
Fit statistics & & & \\
$X^{2}=43.4$, df $=10, p=0.000$ & & & \\
CFI $=0.917$, NFI $=0.922$, GFI $=0.909$, & & & \\
AGFI $=0.901$ & & & \\
RMSEA (root mean square error of & & & \\
approximation) $=0.070$ & & & \\
RMR (root mean square residual) $=0.047$ & & & \\
\hline
\end{tabular}

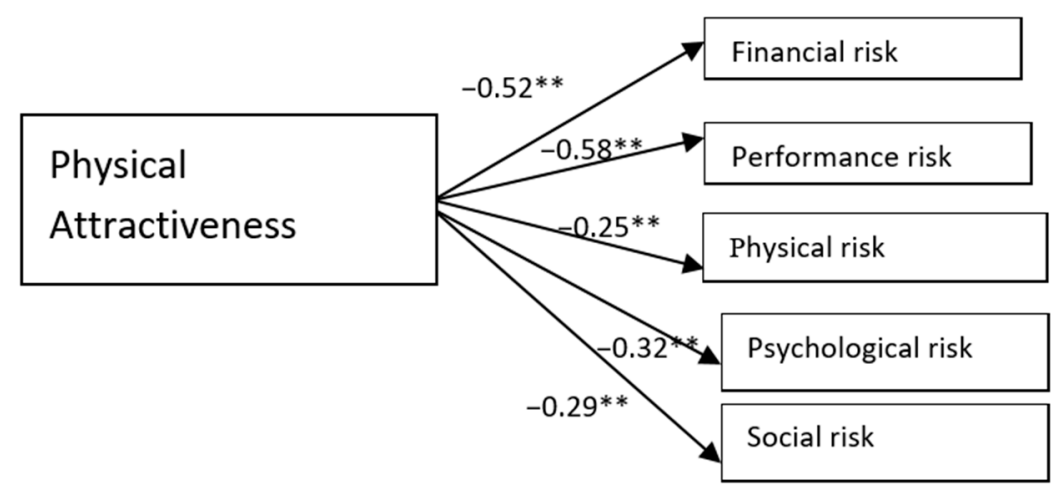

Figure 1. Hypothesized model. ${ }^{* *} p<0.01$.

\section{Conclusions, Discussion, and Managerial Application}

\subsection{Conclusions}

This study contributed by clarifying the relationship between the physical attractiveness of cosmetic medicine servicers and consumers' perceived risk. The findings indicate that physical attractiveness negatively affects perceived financial risk (H1), performance risk (H2), physical risk (H3), psychological risk (H4), and social risk (H5). This study revealed that female cosmetic medicine consumers perceive greater financial, performance, and physical risk than male consumers. Male cosmetic medicine consumers perceive more psychological and social risk than female consumers. Older cosmetic medicine consumers perceive more financial risk than younger consumers. Cosmetic medicine consumers with higher education levels perceive more social risk than consumers with lower education levels. Cosmetic medicine consumers with higher income levels perceive more performance risk than consumers with lower income levels.

\subsection{Discussion}

This study argued that cosmetic medicine is a beauty-related service industry. If the service employee is physically attractive, multiple perceived risks (financial, performance, physical, 
psychological, and social) related to the cosmetic medical service are lower. Professionalism is a key factor affecting consumer trust [64]. If a consumer trusts an employee's expertise and professionalism and recognizes the service they provide as safe and reliable, they are more interested in professional information and cues [51]. Thus, the financial risk of a cosmetic medical service can be reduced, and the consumer will believe that the service has low performance and physical risk. This is in line with the argument of Homburg and Stock (2004) [51], who reported that service employees with high degrees of professionalism and expertise display a positive image, and consumers trust the information and cues provided by them. This study further verified that cosmetic medicine servicers with higher physical attractiveness generate consumer trust, and further reduce the perception of psychological risk.

Furthermore, because of the halo effect of "what is beautiful is good", a physically attractive cosmetic medical service provider results in the consumer's psychological risk being naturally reduced. Finally, because of the expense of cosmetic medicine, the consumer hopes that the results of the service will be appreciated by their peers. If the service provider is physically attractive, this satisfies the vanity of the consumer and reduces their social risk.

In addition, this study also determined that female consumers have greater concern regarding financial, performance, and physical risk, whereas male consumers are more concerned by psychological and social risk. These findings partially support those of Buuk and Dijkstra (2011) [65], who suggested that women are more conscious of their physical appearance and gender, and if they compared themselves with an attractive female model, but not an unattractive one, they were less willing to pay due to the negative comparison. The present study also demonstrated that older consumers are more sensitive to financial risk. This finding supports that of Sirvanci (1993) [66], who revealed that price sensitivity is positively correlated with age. Because cosmetic medicine is regarded as an industry integrating medicine and beauty care, people become more cautious regarding cosmetic medical practices as their age increases. This study also uncovered that educational attainment and social risk are positively correlated. This result indicates that more educated consumers care more about peer recognition of their choices. Finally, the study revealed that income is positively correlated with performance risk. High-income consumers possess better knowledge for accessing impersonal sources of information and select cosmetic medicine based on performance [67]. Therefore, if the service is satisfactory, performance risk is the key factor determining whether high-income cosmetic medicine consumers use the service.

\subsection{Managerial Implications}

This study confirmed that the physical attractiveness of cosmetic medical service personnel has a significant impact on customers' perceived risk. During the consumption process, perceived risk affects consumer intention [41]. If the perceived risk is higher, purchase intention is reduced [68]. Especially in the online world, the "eyeball economy" has become mainstream. Whether a person is an online endorser of cosmetic medicine or physical service provider of medical beauty e-commerce, his or her appearance and composure are the first items assessed during selection. Regarding employee training, improvement of physical attractiveness should be categorized as a training item or appearance should be included as part of performance evaluation to enhance the positive impact of service employees on consumers. In addition, because cosmetic medicine is a highly professional service, the industry should proactively encourage employees to attain educational certifications and experience so that consumers may more positively assess them. Higher capability in a service employee results in enhanced evaluation by consumers. If consumers perceive high professionalism in the service, they have less space for price bargaining. If the industry can provide high quality service and care after treatment, customers' repurchase intention and consumption frequency will be increased.

\section{Limitation and Further Research}

This study was subject to several methodological limitations. First, the cross-sectional design limited our findings. Second, physical attractiveness and risk were measured using a self-report 
scale, and this could have introduced bias. Fourth, the samples comprised only cosmetic medicine consumers; other cosmetic medicine service providers were not sampled.

Gender, age, educational attainment, and income significantly affect various types of risk. Whether these demographic factors have moderating effects on the relationship between the physical attractiveness of cosmetic medicine service providers and risk is a question worth exploring.

Regarding methodology, the methods of data collection and analysis can be divided into qualitative and quantitative. This study used the quantitative method of a questionnaire to verify its hypotheses; thus, the sampling was not complete. In-depth interviews should be conducted to obtain richer findings.

Funding: This research was not funded.

Acknowledgments: This manuscript was edited by Wallace Academic Editing.

Conflicts of Interest: The author declares no conflict of interest.

\section{References}

1. Chen, G. Beauty Economics, not only Face and Color Economics. Bus. Coll. 2018, 1, 41-43.

2. China News Center. China's Beauty consumption boom after 90 became the main force. United News, 10 January 2020; B1, Taiwan Business News.

3. Cash, R.F.; Gillen, B.; Burns, D.S. Sexism and beautyism in personnel consulting decision making. J. Appl. Psychol. 1977, 62, 301-310. [CrossRef]

4. Jin, J.; Fan, B.; Dai, S.; Ma, Q. Beauty premium: Event-related potentials evidence of how physical attractiveness matters in online peer-to-peer lending. Neurosci. Lett. 2017, 640, 130-135. [CrossRef] [PubMed]

5. Ma, Q.; Qian, D.; Hu, L.; Wang, L. Hello handsome! Male's facial attractiveness gives rise to female's fairness bias in Ultimatum Game Scenarious—An ERP study. PLoS ONE 2017, 12, e0180459. [CrossRef]

6. Ford, R.; Price, G.; Hollmeyr, K.B.; Chiba, M. Brains versus beauty in the knowledge economy. J. Hum. Resour. Manag. 2018, 16, 1683-7584. [CrossRef]

7. Business Editors, Medical/Health Writers. Bid for Surgery Launches Online; E-exchange for Cosmetic surgery Links Patients and doctors. Business Wire, New York, 06 March 2000; 1.

8. Hilton, L. Next-generation technologies. Dermatol. Times Monmouth Junction 2019, 39, 5-48.

9. Patzer, G.L. Source credibility as a function of communicator physical Attractiveness. J. Bus. Res. 1983, 11, 229-241. [CrossRef]

10. Koerning, S.K.; Page, A.L. What if your dentist looked like Tom Cruise? Applying the match-up hypothesis to a service encounter. Psychol. Mark. 2002, 19, 91-110. [CrossRef]

11. Patzer, G. Ethics concerning physical attractiveness phenomenon: Business strategy versus research knowledge. J. Acad. Bus. Ethics 2011, 3, 13.

12. Greitemeyer, T.; Kunz, I. Name-Valence and Physical Attractiveness in Facebook: Their Compensatory Effects on Friendship Acceptance. J. Soc. Psychol. 2013, 153, 257. [CrossRef]

13. Eastwick, P.W.; Eagly, A.H.; Finkel, E.J.; Johnson, S.E. Implicit an duplicity preferences for physical attractiveness in a romantic partner: A double dissociation in predictive validity. J. Personal. Soc. Psychol. 2011, 101, 993-1011. [CrossRef] [PubMed]

14. Bower, A.B.; Ladreth, S. Is beauty best? Highly versus normally attractive models in advertising. J. Advert. 2001, 30, 1-12. [CrossRef]

15. Baker, M.J.; Churchill, A.G., Jr. The impact of physically attractive models on advertising evaluations. J. Mark. Res. 1977, 14, 538-555. [CrossRef]

16. Carswell, K.L.; Finkel, E.J.; Kumashiro, M. Interpersonal Relations and Group Processes. J. Personal. Soc. Psychol. 2019, 116, 919-941. [CrossRef]

17. Eulerich, M.; Theis, J.C.; Lao, J.; Ramon, M. Do fine feathers make a fine bird? The influence of attractiveness on fraud-risk judgments by internal auditors. Int. J. Audit. 2018, 22, 332-344. [CrossRef]

18. Wu, L.; Fung So, K.K.; Xiong, L.; King, C. The impact of employee conspicuous consumption cue and physical attractiveness on consumers' behavioral responses to service failures. Int. J. Fo Contemp. Hosp. Manag. 2019, 31, 21-40. [CrossRef] 
19. Jajodia, I.; Jain, K.; Gautam, S. The Determinants of Selfie-Clicking Behavior. IUP J. Manag. Res. 2019, 18, 64-78.

20. Milfelner, B.; Kikel, T.V.; Mumel, D.; Pisnik, A. Segmenting female consumers: High-involvement personal services. Int. J. Retail Distrib. Manag. 2017, 45, 485-497. [CrossRef]

21. Stokes, R.; Frederick, R.C. Women's perceived body images: Relations with personal happiness. J. Women Aging 2003, 15, 17-29. [CrossRef]

22. Lee, J. Botox? Smooth out the risks. Med. Econ. 2002, 79, 65.

23. Morrow, P.C. Physical attractiveness and selection decision making. J. Manag. 1990, 16, 45-60. [CrossRef]

24. Riggio, R.E.; Widaman, K.F.; Tucker, J.S.; Salinas, C. Beauty is more than skin deep: Component of attractiveness. Basic Appl. Soc. Psychol. 1991, 12, 423-439. [CrossRef]

25. Burns, G.L.; Farina, A. Physical attractiveness and self-perception of mental disorder. J. Abnorm. Psychol. 1987, 96, 161-163. [CrossRef] [PubMed]

26. Hatfield, E.; Forbes, M.; Rapson, R.L. Marketing Love and Sex. Society 2012, 49, 506-511. [CrossRef]

27. Schneider, D.J. Implicit personality theory: A review. Psychol. Bull. 1973, 79, 294-309. [CrossRef]

28. Little, A.C. Facial appearance and leader choice in different contexts: Evidence for task contingent selection based on implicit and learned face-behaviour/face-ability associations. Leadersh. Q. 2014, 25, 865-874. [CrossRef]

29. Eagly, A.H.; Ashmore, R.D.; Longo, L.C. What is beautiful is good, but ... .: A meta-analytic review of research on the physical attractiveness stereotype. Psychol. Bull. 1991, 110, 109-128. [CrossRef]

30. Rohner, J.C.; Rasmussen, A. Physical attractiveness stereotype and memory. Scand. J. Psychol. 2011, 52, 309-319. [CrossRef]

31. Joseph, W.B. The credibility of physically attractive communications: A review. J. Advert. 1982, 11, 15-24. [CrossRef]

32. Addis, F.S.; Myers, C. Brand Identity: The Power of First Impressions. Rough Notes 2012, 155, 88-90.

33. Dion, K.; Berscheid, E.; Walster, E. What a beautiful is good. J. Personal. Soc. Psychol. 1972, 24, $285-290$. [CrossRef] [PubMed]

34. Solomon, B.C.; Vazire, S. You are so beautiful...to me: Seeing beyond biases and achieving accuracy in romantic relationships. J. Personal. Soc. Psychol. 2014, 107, 516. [CrossRef]

35. Li, Z.; Sha, Y.; Song, X.; Yang, K.; Zhao, K. Impact of risk perception on customer purchase behavior: A meta-analysis. J. Bus. Ind. Mark. 2020, 35, 76-96. [CrossRef]

36. Dowling, G.R.; Staelin, R. A model of and intended risk-handling activity. J. Consum. Res. 1994, 21, 119-134. [CrossRef]

37. Baird, I.S.; Thomas, H. Toward a Contingency Model of Strategic Risk Taking. Acad. Manag. Rev. 1985, 10, 230. [CrossRef]

38. Cox, D.F. Risk Taking and Information Handing in Consumer Behavior-An Intensive Study of Two Cases; Harvard University Press: Boston, MA, USA, 1967; pp. 34-81.

39. Dowling, G.R. Perceived Risk: The Concept and its measurement. Psychol. Mark. 1986, 3, 193-210. [CrossRef]

40. Chaudhuri, A. Product Class Effects on Perceived Risk: The Role of Emotion. Int. J. Res. Mark. 1998, 152, 157-168. [CrossRef]

41. Kansal, P.; Goel, S. Perceived Recourse and Redress Risk: Remedy risk Before Purchase and its Impact on Purchase Intention. IUP J. Manag. Res. 2019, 18, 51-66.

42. Rosillo-Díaz, E.; Blanco-Encomienda, F.J.; Crespo-Almendros, E. A cross-cultural analysis of perceived product quality, perceived risk and purchase intention in e-commerce platforms. J. Enterp. Inf. Manag. 2019, 33, 139-160. [CrossRef]

43. Till, B.D.; Busler, M. The match-up hypothesis: Physical attractiveness, expertise, and the role of fit on brand attitude, purchase intent, and brand beliefs. J. Advert. 2000, 29, 1-14. [CrossRef]

44. Ferguson, L. Gaining (From) Your Clients Trust. J. Account. 2012, 213, 38-40.

45. Kasper-Fuehrera, E.C.; Ashkanasy, N.M. Communicating trustworthiness and building trust in interoganizational virtual organizations. J. Manag. 2001, 27, 235-254.

46. Szulanski, G.; Cappetta, R.; Jesen, R.J. When and how trustworthiness matters. Knowledge transfer and the moderating effect of causal ambiguity. Organ. Sci. 2004, 15, 600-613. [CrossRef]

47. Jacoby, J.; Kaplan, B. The Components of Perceived Risk. Assoc. Consum. Res. 1972, 3, 382-386. 
48. Grewal, D.; Gotlieb, J.; Marmorstein, H. The Moderating Effects of Message Framing and Source Credibility on the Price-perceived Risk Relationship. J. Consum. Res. 1994, 21, 145-153. [CrossRef]

49. Koerning, S.K. The Physical Attractiveness Effect in the Service Setting: An Examination of the Role of Similarity. Ph.D. Thesis, University of Illinois at Chicago, Chicago, IL, USA, 2000. ProQuest Dissertations Publishing, 9978620.

50. Abass, K.; Ganle, J.K.; Afriyie, K. 'The germs are not harmful': Health risk perceptions among consumers of peri-urban grown vegetable in Kumasi, Ghana. GeoJournal 2017, 82, 1213-1227. [CrossRef]

51. Homburg, C.; Stock, R.M. The Link Between Salespeople's Job Satisfaction and Customer Satisfaction in a Business-to-Business Context: A Dyadic Analysis. Acad. Mark. Sci. 2004, 32, 144-158. [CrossRef]

52. Campbell, M.C.; Goodstein, R.C. The moderating effect of perceived on consumers' evaluations of product incongruity: Preference for the norm. J. Consum. Res. 2001, 28, 439-450. [CrossRef]

53. McDaniels, T.; Axelrod, L.; Slovic, P. Characterising perception of ecological risk. Risk Anal. 1995, 15, 575-588. [CrossRef]

54. Hlasny, V. A Hierarchical Process of Applicant Screening by Korean Employers. J. Labor Res. 2014, 35, 246-270. [CrossRef]

55. Rohrmann, B. Risk perception of different societal groups: Australian findings and cross-national comparisons. Aust. J. Psychol. 1994, 46, 150-163. [CrossRef]

56. Podsakoff, P.M.; Organ, D.W. Self-reports in organizational research: Problems and prospects. J. Manag. 1986, 12, 531-544. [CrossRef]

57. Ohanian, R. Construction and Validation of a Scale to Measure Celebrity Endorsers' Perceived Expertise, Trustworthiness, and Attractiveness. J. Advert. 1990, 19, 39-52. [CrossRef]

58. McGorry, S.Y. Measurement in a cross-cultural environment: Survey translation issues. Qual. Mark. Res. Int. J. 2000, 3, 74-81. [CrossRef]

59. Anderson, J.C.; Gerbing, D.W. Structural equation modeling in practice: A review and recommended two-step approach. Psychol. Bull. 1988, 103, 411-423. [CrossRef]

60. Niehoff, B.P.; Moorman, R.H. Justice as a mediator of the relationship between methods of monitoring and organizational citizenship behavior. Acad. Manag. J. 1993, 36, 527-556.

61. Netemeyer, R.G.; Brashear-Alejandro, T.; Boles, J.S. A cross-national model of job-related outcomes of work role and family role variables: A retail sales context. J. Acad. Mark. Sci. 2004, 32, 49-60. [CrossRef]

62. Nunnally, J.C. Psychometric Theory, 2nd ed.; McGraw-Hill: New York, NY, USA, 1978.

63. Tabachnick, B.G.; Fidell, L.S. Using Multivariate Statistics, 3rd ed.; Haper Collins College Publishers: New York, NY, USA, 1996.

64. Swan, J.E.; Trawick, I.F.; Silva, D.W. How industrial sale people gain customer trust. Ind. Mark. Manag. 1985, 14, 203-211. [CrossRef]

65. Buuk, A.P.; Dijkstra, P. Does attractiveness sell? Women's attitude toward a product as a function of model attractiveness, gender printing, and social comparison orientation. Psychol. Mark. 2011, 28, 958-973.

66. Sirvanci, M.B. An Empirical Study of Price Thresholds and Price Sensitivity. J. Appl. Bus. Res. 1993, 9, 43-49. [CrossRef]

67. Kaur, I. Mutual fund investor's behavior towards information search and selection criteria. Qual. Res. Financ. Mark. 2018, 10, 395-414. [CrossRef]

68. Garretson, J.A.; Clow, K.E. The influence of coupon face value on service quality expectations, risk perceptions and purchase intentions in the dental industry. J. Serv. Mark. 1999, 13, 59-72. [CrossRef]

(C) 2020 by the author. Licensee MDPI, Basel, Switzerland. This article is an open access article distributed under the terms and conditions of the Creative Commons Attribution (CC BY) license (http://creativecommons.org/licenses/by/4.0/). 